\title{
STABILITY ANALYSIS OF CYLINDRICAL SHELLS SUBJECTED TO COMPLEX LOADS
}

\author{
NGo HuONG NHu \\ Institute of Mechanics 264 Doi Can, Hanoi, Vietnam
}

\begin{abstract}
The paper deals with stability analysis of shell on the basis FEM via Castem 2000. The numerical results of stability problems of cylinders subjected to different loads as compress load, pressure, concentrated and combined loads are compared with analytical result and give a good agreement. The influence of changing radius of the cylindrical shell on the unstable forms and the influence of angles of fibers on unstable behaviour of laminated composite shell are considered. Numerical results and corresponding programs by languages Gibian given in the paper to realize software Castem 2000 can be applied in the design and in the stability analysis of the shell with more complex conditions.
\end{abstract}

1. General equations and solutions for the stability problem

The system of equations for the stability problem of shell with small deflections $[1]$ is

$$
\begin{aligned}
D \nabla^{4} w & =\nabla_{k}^{2} \varphi+q \\
\frac{1}{h} \nabla^{4} \varphi & =-\nabla_{k}^{2} w
\end{aligned}
$$

where $w$ is a function of deflection and $\varphi$ is a stress function.

In the Cartesian coordinates, we have:

$$
q=-h\left(p_{x} \frac{\partial^{2} w}{\partial x^{2}}+p_{y} \frac{\partial^{2} w}{\partial y^{2}}+2 s \frac{\partial^{2} w}{\partial x \partial y}\right)
$$

and the system of equations can be reduced into an eight-order equation:

$$
\frac{D}{h} \nabla^{8} w+\frac{E}{R^{2}} \frac{\partial^{4} w}{\partial x^{4}}+p_{x} \nabla^{4}\left(\frac{\partial^{2} w}{\partial x^{2}}\right)+p_{y} \nabla^{4}\left(\frac{\partial^{2} w}{\partial y^{2}}\right)+2 s \nabla^{4}\left(\frac{\partial^{2} w}{\partial x \partial y}\right)=0 .
$$

a. Circular cylindrical shell subjected to axial compressed distributed in plane force $p$

In this case the values $p_{y}=0 ; s=0$, the minimum possible critical stress has the form [1]:

$$
\bar{P}^{*}=\frac{1}{\sqrt{3\left(1-\nu^{2}\right)}} E \frac{h}{R}
$$


when $\nu=0.3$ then $\bar{P}^{*}=0.605 E \frac{h}{R}$.

b. Circular cylindrical shell subjected to pressure $q$.

In this case the values $p_{x}=0 ; p_{y} \neq 0 ; s=0$, the minimum possible critical pressure is:

$$
\begin{aligned}
& q=0.92 E\left(\frac{R}{L}\right)\left(\frac{h}{R}\right)^{2.5} \quad \text { for the middle cylinder and } \\
& q=\frac{3 D}{R^{3}}=\frac{E}{4\left(1-\nu^{2}\right)}\left(\frac{h}{R}\right)^{3} \text { for the long cylinder. }
\end{aligned}
$$

c. Circular cylindrical shell subjected to a combination of pressure $q$ and compressible loads

Then $p_{x} \neq 0 ; p_{y} \neq 0 ; s=0$ and the critical pressure is:

$$
q=\frac{E\left(\frac{h}{R}\right)^{2}}{\left[0,83+1,1 \frac{L}{R} \sqrt{\frac{R}{h}}\right]}
$$

These results represent the upper bound of the actual collapse load, which will be compared later with numerical result of solution by FEM.

2. The Finite Element Method in the stability problem

The problem of stability of plate and shell lead to solve an equation of the type [3] by FEM:

$$
[\mathbf{K}]\{\boldsymbol{\delta}\}+\left[\mathbf{K}_{G}\right]\{\boldsymbol{\delta}\}=\{\mathbf{P}\} .
$$

Let system of stresses and body forces can be increased linearly by some scaling factor $\lambda$, when the new value of $\left[\mathbf{K}_{G}\right]$ will be :

$$
\left[\mathbf{K}_{G}\right]=\lambda\left[\mathbf{K}_{G}\right]
$$

Thus, the condition of existing distortion of equilibrium state of shell without external loads can be written as :

$$
\left([\mathbf{K}]+\lambda\left[\mathbf{K}_{G}\right]\right)\{\boldsymbol{\delta}\}=0 .
$$

In general it is possible to find non trivial values of $\lambda$ and "modal shapes" of $\{\delta\}$ for which the above equation is satisfied. This is the same problem as the classical "eigenvalue" problem:

$$
\left([\mathbf{K}]-\omega^{2} \cdot[M]\right)\{\delta\}=0
$$

In practice, we are interested only in the lowest value of $\lambda$ and its associated mode. 
The main steps to solve stability problem by FEM are followings: 1. Determination of the assembled stiffness matrix

$$
[\mathbf{K}]=\sum_{m=1}^{N}[\mathbf{k}]_{m}^{e}
$$

where $[\mathbf{k}]_{m}^{e}=\int_{V}\left[\mathbf{B}^{m}\right]^{T} \mathbf{C}^{m}\left[\mathbf{B}^{m}\right] d V$ is an element stiffness matrix,

$\mathbf{B}^{m}$ is a matrix of relations between strains and displacements $\varepsilon^{m}=\mathbf{B}^{m} \mathbf{U}$

$\mathbf{C}^{m}$ is matrix of relation between stress and strains $\boldsymbol{\sigma}^{m}=\mathbf{C}^{m} \varepsilon^{m}+\sigma^{i m}$

2. Determination of stress distributions $\{\sigma\}$ before unstable state by solving equation:

$$
[\mathbf{K}]\{\delta\}=\{\mathbf{P}\}
$$

3. Definition of $\left[\mathbf{K}_{G}\right]^{e},\left[\mathbf{K}_{G}\right]$ - "Initial stress stiffness matrix" from stress distributions $\{\sigma\}$

4. Solve eigenvalue problem, instead of $[M]$ in the (2.2) the expression $(-1) *\left[\mathbf{K}_{G}\right]$ is taken. The received eigenvalues $\lambda=(2 \pi \omega)^{2}$ will be the ratio of corresponding buckling loads $P_{c r}$ to the axial load $P$ applied in the linear prebuckling analysis. Then critical stress can be found in the form $\sigma_{c r}=\lambda \sigma_{\max }$.

5. In the case of laminate composite shell, instead of $\mathbf{C}^{m}$ we have to pay attention to:

a. The relations between stress and strain in $k$-th laminar [2]:

$$
\sigma_{k}(M)=Q_{k}^{\prime} \varepsilon_{m}(x, y)+z Q_{k}^{\prime} k(x, y) ; \quad Q_{k}^{\prime}=\left[Q_{i j}^{\prime}\right]_{k}
$$

where $h_{k-1} \leq z \leq h_{k} ; z$ - is the distance from the point $\mathrm{M}$ to middle surface.

b. The relations between stress and strain for plate element of $n$-layers [2]:

$$
\begin{aligned}
& {\left[\frac{N}{M_{b}}\right]=\left[\frac{A}{B} \frac{B}{D}\right] \cdot\left[\frac{\varepsilon_{m}}{k}\right] ; \quad \mathbf{A}=\left[A_{i j}\right] ; \quad \mathbf{B}=\left[B_{i j}\right] ; \quad A_{i j}=\sum_{k=1}^{n}\left(h_{k}-h_{k-1}\right)\left(Q_{i j}^{\prime}\right)_{k}} \\
& B_{i j}=\frac{1}{2} \sum_{k=1}^{n}\left(h_{k}^{2}-h_{k-1}^{2}\right)\left(Q_{i j}^{\prime}\right)_{k} ; \quad \mathbf{D}=\left[D_{i j}\right] ; \quad D_{i j}=\frac{1}{3} \sum_{k=1}^{n}\left(h_{k}^{3}-h_{k-1}^{3}\right)\left(Q_{i j}^{\prime}\right)_{k} \\
& Q_{i j}^{\prime}=C_{i j}^{\prime}-\frac{C_{i 3}^{\prime} C_{j 3}^{\prime}}{C_{33}^{\prime}} \quad i, j=1,2,6 \text { - reduced stiffness coefficients. }
\end{aligned}
$$

Thus, knowing characteristics of composite material of each layer we can calculate the element stiffness matrix for n-laminate composite and return to step 2.

3. Some numerical results of stability problems of cylindrical shells subjected to complex loads via Castem 2000

1. Numerical result in comparison with the analytical result

a. Consider stability problem of a circular isotropic cylindrical shell subjected 
to axial compressed in plane distributed load $P=500 \mathrm{~N}$, two ends of cylinder are simply supported. The data of cylinder are given: thickness $h=0.004 \mathrm{~m}$, radius $R=0.6 \mathrm{~m}$ and length $L=2 \mathrm{~m}$. Here the condition for the shell with middle length: $1.38 \sqrt{\frac{h}{R}}<\frac{L}{R}<0.57 \sqrt{\frac{R}{h}}$ is satisfied [1]. The characters of material of cylinder are: $E=2.1 \cdot 10^{11} \mathrm{~N} / \mathrm{m}^{2} ; \nu=0.3$. The cylinder is divided into 720 shell elements with 384 nodes (six degrees freedom at each node) The numerical result shows that: the lowest value of the frequency eigenvalue is: $\omega=29.351 \mathrm{~Hz}$.

The calculated critical stress is:

$$
P_{c r c}=\lambda \cdot \sigma_{\max }=(2 \pi \omega)^{2} \times \sigma_{\max }=8.71077 \cdot 10^{8} \mathrm{~N} / \mathrm{m}^{2}
$$

The theoretical critical stress according to $(1.4)$ is :

$$
P_{\text {crt }}=P^{*}=8.4700 \cdot 10^{8} \mathrm{~N} / \mathrm{m}^{2} \text {. }
$$

The error between these values is enough small:

$$
\frac{a b s\left(P_{c r t}-P_{c r c}\right)}{P_{c r t}} \times 100=2.8426 \%
$$

\section{b. Cylindrical shell}

For long cylindrical shell. Consider the stability problem of a circular isotropic long cylindrical shells subjected to outside pressure $q=-100 \mathrm{~N} / \mathrm{m}^{2}$, two ends of cylinder are simply supported and free. The characters of material of cylinder are $E=2.1 \cdot 10^{11} \mathrm{~N} / \mathrm{m}^{2} ; \nu=0 . \dot{3}$.

The numerical results are compared with analytical solution (1.6) and given in the table 1.

Table 1

\begin{tabular}{lcccc}
\hline $\begin{array}{l}\text { Cylinder } \\
(\mathrm{m})\end{array}$ & $\omega(\mathrm{Hz})$ & $\begin{array}{c}\text { Calculated } \\
\text { critical } \\
\text { pressure }(\mathrm{Pa})\end{array}$ & $\begin{array}{c}\text { Theoretical } \\
\text { critical } \\
\text { pressure }(\mathrm{Pa})\end{array}$ & $\begin{array}{c}\text { Error \% between } \\
\text { calculated and } \\
\text { theoretical result }\end{array}$ \\
\hline $\begin{array}{l}L=6 ; \\
R=0.6 ;\end{array}$ & 91.596 & $3.30859 \mathrm{E} 7$ & $3.17969 \mathrm{E} 7$ & 4.0538 \\
$L / R=10$ & & & & \\
$L=10 ;$ & & & & \\
$\begin{array}{l}L=0.5 ; \\
L / R=20\end{array}$ & 118.4 & $5.56684 \mathrm{E} 7$ & $5.49451 \mathrm{E} 7$ & \\
$L=40 ;$ & & & & \\
$R=1$ & 41.859 & $6.91736 \mathrm{E} 6$ & $6.86813 \mathrm{E} 6$ & 0.7163 \\
$L / R=40$ & & & & \\
\hline
\end{tabular}


One notes that the ratio $L / R$ is greater, obtained results are nearly to theoretical results.

For short cylinders subjected to pressure

Consider cylinders in the same above conditions of loading, material and following geometry characteristics:

1. $R / L=0.4$ and $R / L=[800 ; 915 ; 1000 ; 1067]$. Calculated results are compared with theoretical ones (1.5) we see that the ratio $R / h$ has an influence in error (see table 2).

2. $R / h=800$ and $R / L=[2.5 ; 2.375 ; 2.25]$. Calculated results are compared with theoretical (1.5) (table 3)

Table 2

\begin{tabular}{ccccccl}
\hline $\begin{array}{c}R \\
(\mathrm{~m})\end{array}$ & $\begin{array}{c}L \\
(\mathrm{~m})\end{array}$ & $\begin{array}{c}h \\
(\mathrm{~m})\end{array}$ & $R / h$ & $\begin{array}{c}\text { Calculated } \\
\text { critical } \\
\text { pressure(Pa) }\end{array}$ & $\begin{array}{c}\text { Theoretical } \\
\text { critical } \\
\text { pressure(Pa) }\end{array}$ & $\begin{array}{l}\text { Error \% between } \\
\text { calculated and } \\
\text { theoretical result }\end{array}$ \\
\hline & - & - & - & - & & \\
0.4 & 1 & 0.0005 & 800 & 3871.6 & 4065.9 & 4.776 \\
0.8 & 2 & 0.001 & 800 & & & \\
3.2 & 8 & 0.004 & 800 & & & \\
3.2 & 8 & 0.0035 & 915 & 2913.8 & 2911.9 & 0.065826 \\
3.2 & 8 & 0.0032 & 1000 & 2432.8 & 2327.4 & 4.5253 \\
3.2 & 8 & 0.003 & 1067 & 2073.9 & 1980.6 & 0.72478 \\
\hline
\end{tabular}

Table 3

\begin{tabular}{|c|c|c|c|c|c|c|}
\hline $\begin{array}{c}R \\
(\mathrm{~m})\end{array}$ & $\begin{array}{c}L \\
(\mathrm{~m})\end{array}$ & $\begin{array}{c}h \\
(\mathrm{~m})\end{array}$ & $L / R$ & $\begin{array}{l}\text { Calculated } \\
\text { critical } \\
\text { pressure }(\mathrm{Pa})\end{array}$ & $\begin{array}{l}\text { Theoretical } \\
\text { critical } \\
\text { pressure }(\mathrm{Pa})\end{array}$ & $\begin{array}{l}\text { Error } \% \text { between } \\
\text { calculated and } \\
\text { theoretical result }\end{array}$ \\
\hline 0.8 & 2 & 0.001 & 2.5 & 3871.6 & 4065.9 & 4.776 \\
\hline 0.8 & 1.9 & 0.001 & 2.375 & 4262.8 & 4219.9 & 0.39872 \\
\hline 0.8 & 1.8 & 0.001 & 2.25 & 4691.7 & 4517.6 & 3.8526 \\
\hline
\end{tabular}

c. Cylinder subjected to complex load

Consider circular isotropic cylindrical shells subjected to complex loads: outside pressure $q=-100 \mathrm{~N} / \mathrm{m}^{2}$, axial compression $p=50 \mathrm{~N}$ and concentrated load $F_{y}=$ $80 \mathrm{~N}$ at point $P(R, 0,0)$. Two ends of cylinder are simply supported and free. The characters of material of cylinder are $E=2.1 \cdot 10^{11} \mathrm{~N} / \mathrm{m}^{2} ; \nu=0.3 ; R=0,8 \mathrm{~m}$; $L=2 \mathrm{~m} ; h=0.001 \mathrm{~m}$.

The results are compared with (1.7) and presented in the table 4: 
Table 4

\begin{tabular}{lccccc}
\hline Loads & $\begin{array}{c}\text { Frequency } \\
(\mathrm{Hz})\end{array}$ & $\begin{array}{c}\text { Calculated } \\
\text { critical } \\
\text { pressure }(\mathrm{Pa})\end{array}$ & $\begin{array}{c}\text { Theoretical } \\
\text { critical } \\
\text { pressure (Pa) }\end{array}$ & $\begin{array}{c}\text { Error } \\
\%\end{array}$ \\
\cline { 1 - 2 } $\begin{array}{l}\text { Pressure } \\
\begin{array}{l}\text { Pressure and } \\
\text { compressible loads }\end{array}\end{array}$ & 0.99030 & 3871.6 & 4065.9 & 4.776 \\
$\begin{array}{l}\text { Combination of } \\
\text { pressure, compression } \\
\text { and concentrated }\end{array}$ & 0.98416 & 3823.7 & 3975.2 & 3.8108 \\
loads & & & & & \\
\hline
\end{tabular}

\section{Note that:}

- In general the calculated results give a good agreement with theoretical ones in many cases with different loads and combined loads.

- For shorts cylinders the error depends on ratios $R / L$ or $R / h$ and one needs more careful when applying this software.

- The critical pressure is smaller when the cylinder is subjected to complex loads.

\section{The influence of the radius of the shell on the critical loads and} unstable forms

Consider the cylinder with the same characteristics but various radius $R=0.5 \mathrm{~m}$; $0.4 \mathrm{~m} ; 0.3 \mathrm{~m} ; 0.2 \mathrm{~m}$ and $L=8 \mathrm{~m} ; h=0.005 \mathrm{~m}$. The numerical results are shown in the table 5 .

Table 5

\begin{tabular}{|c|c|c|}
\hline$R(\mathrm{~m})$ & $\omega(\mathrm{Hz})$ & $\begin{array}{c}\text { Critical calculate stress: } P \cdot 10^{3} \\
(\mathrm{MPa})\end{array}$ \\
\hline 0.5 & 33.848 & 1.47272 \\
\hline 0.4 & 31.520 & 1.61183 \\
\hline 0.3 & 32.580 & 2.31375 \\
\hline 0.2 & 25.819 & 2.19192 \\
\hline
\end{tabular}

Note that:

- The critical loads increase when the radius are reduced (see Table 5)

- The unstable forms are changed (see fig 1-3) with different $R$. 


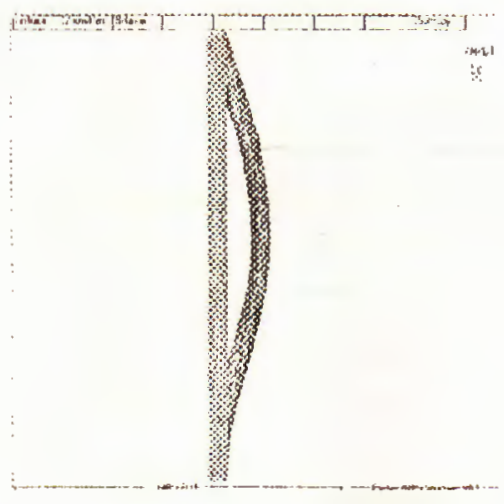

Fig. 1. The unstable form in global when $R=0.2 \mathrm{~m}$

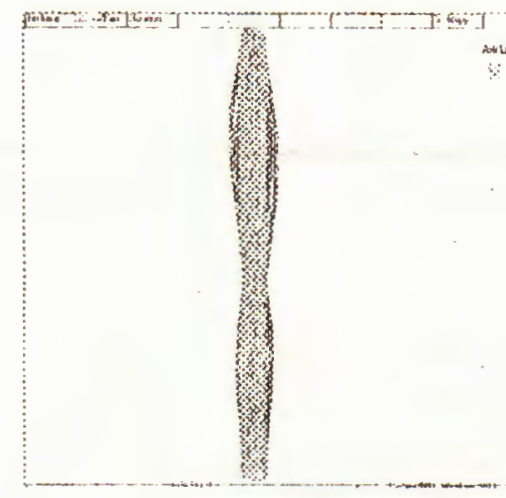

Fig. 2. The unstable form when $R=0.3 \mathrm{~m}$

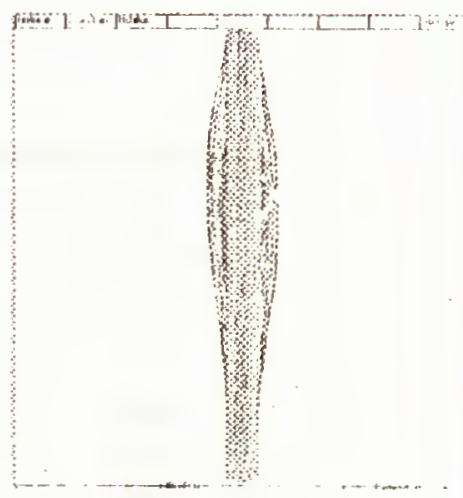

Fig. 3. The unstable form when $R=0.4 \mathrm{~m}$

\section{Influence of the length of the shell on the critical stress}

Consider the cylinders with the same material characteristics but $R=0.6 \mathrm{~m}$, $h=0.01 \mathrm{~m}, P=5000 \mathrm{~N}$ and various length: $L=8 \mathrm{~m}, 9 \mathrm{~m}, 10 \mathrm{~m}, 12 \mathrm{~m}$. The numerical results are presented in table 6 .

\section{Table 6}

\begin{tabular}{|c|c|c|c|}
\hline$L(\mathrm{~m})$ & $\omega(\mathrm{Hz})$ & $\begin{array}{l}\text { Calculated critical } \\
\text { stress: } P \cdot 10^{3}(\mathrm{MPa})\end{array}$ & $\begin{array}{c}\text { Classical critical } \\
\text { stress } P * .10^{3}(\mathrm{MPa})\end{array}$ \\
\hline 8 & 19.707 & 2.05597 & 2.11750 \\
\hline 9 & 19.313 & 1.99060 & \\
\hline 10 & 19.250 & 1.98891 & \\
\hline 12 & 19.677 & 2.09384 & \\
\hline
\end{tabular}

\section{Stability of the composite shell}

Consider the cylinder $R=0.6 \mathrm{~cm} ; L=2 \mathrm{~m} ; t=0,004 \mathrm{~m}$ under compressible loads $P=-500 \mathrm{~N}$. It is made from two layer laminar composite material with characteristic $E_{1}=7 \cdot 10^{6} \mathrm{~N} / \mathrm{m}^{2} ; E_{2}=1.3 \cdot 10^{6} \mathrm{~N} / \mathrm{m}^{2} ; \nu_{12}=0.28 ; G_{X}=5 \cdot 10^{5} \mathrm{~N} / \mathrm{m}^{2}$. The thickness of each laminar is equal to $t_{k}=0.002 \mathrm{~m}$ The following angles of fiber directions are considered in this paper: $\theta=30^{\circ} /-30^{\circ} ; 45^{\circ} /-45^{\circ} ; 60^{\circ} /-60^{\circ}$; $75^{\circ} \%-75^{\circ}$.

\section{The boundary conditions}

- One end of cylinder is simply supported: $u_{x}=0 ; u_{y}=0 ; u_{z}=0$, and the other end $u_{x}=0 ; u_{y}=0$.

- Compressible load acting at both ends of shell $F_{x}=-500 \mathrm{~N}$.

The numerical results are given in the table 7 and the unstable forms are shown in figures $(4,5,6,7)$. 
Table 7

\begin{tabular}{cccccc}
\hline $\begin{array}{c}\alpha^{\circ} \\
\left(\alpha^{\circ} /-\alpha^{\circ}\right)\end{array}$ & $\omega(\mathrm{Hz})$ & $\lambda$ & $\begin{array}{c}\sigma_{x x} 1 \text { th-layer } \\
\left(\mathrm{N} / \mathrm{m}^{2}\right)\end{array}$ & $\begin{array}{c}\sigma_{x x} \text { 2th-layer } \\
\left(\mathrm{N} / \mathrm{m}^{2}\right)\end{array}$ \\
\cline { 1 - 2 } 75 & & 0.17385 & 1.1932 & 14530 & 14599 \\
60 & 0.16977 & 1.1378 & 17273 & 18117 \\
45 & 0.23453 & 2.1716 & & 18783 & 18646 \\
30 & 0.22056 & 1.9205 & 16734 & 16552 \\
\hline
\end{tabular}

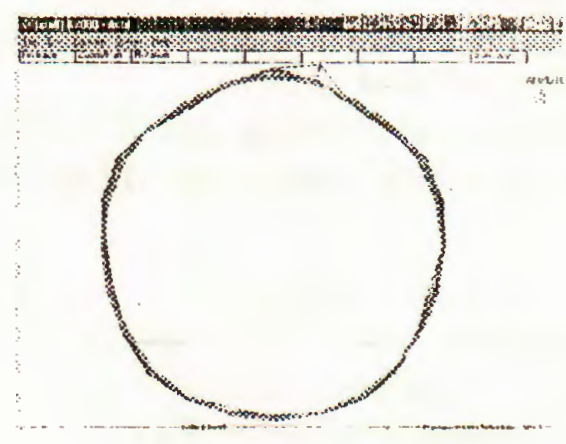

Fig. 4. The unstable forms in the direction of circulation when $\alpha=30^{\circ}$

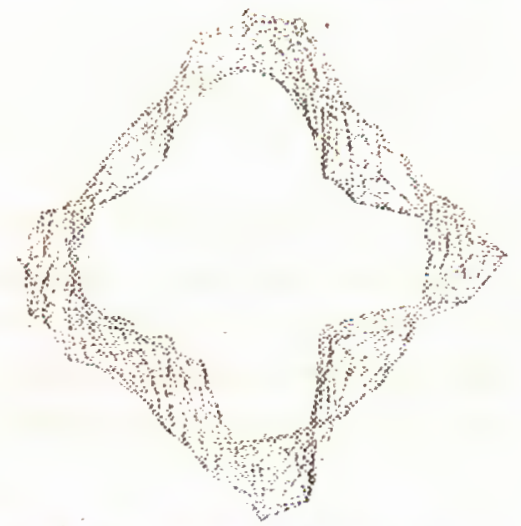

Fig. 6. The unstable forms in the direction of circulation when $\alpha=60^{\circ}$

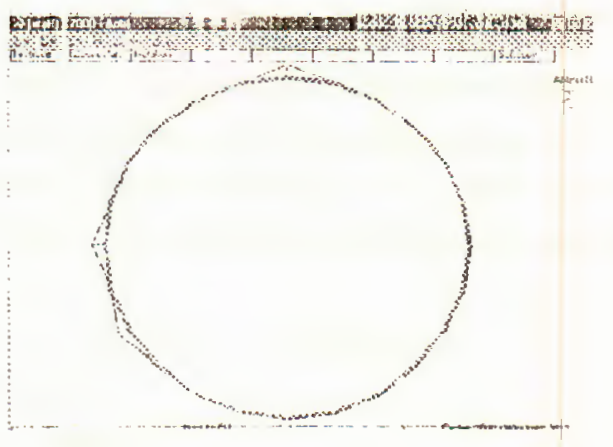

Fig. 5. The unstable forms in the direction of circulation when $\alpha=45^{\circ}$

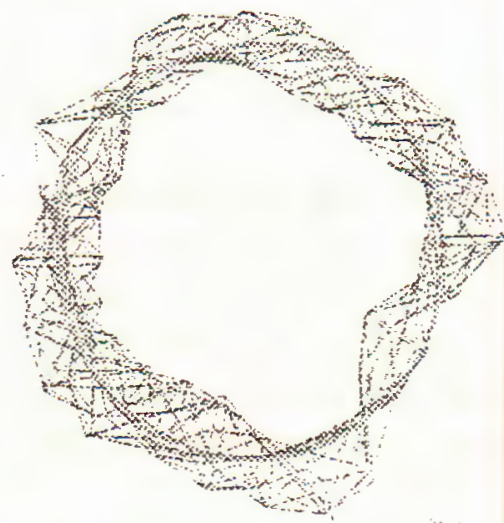

Fig. 7. The unstable forms in the direction of circulation when $\alpha=75^{\circ}$

\section{Remarks}

- The above investigated shell is more stable when angle of fiber $\alpha=45^{\circ}$ and easier unstable when $\alpha=60^{\circ}$

- The unstable forms in the direction circulation of the shell depend on the angle of the fibers (see fig $4,5,6,7,8,9$ ) 


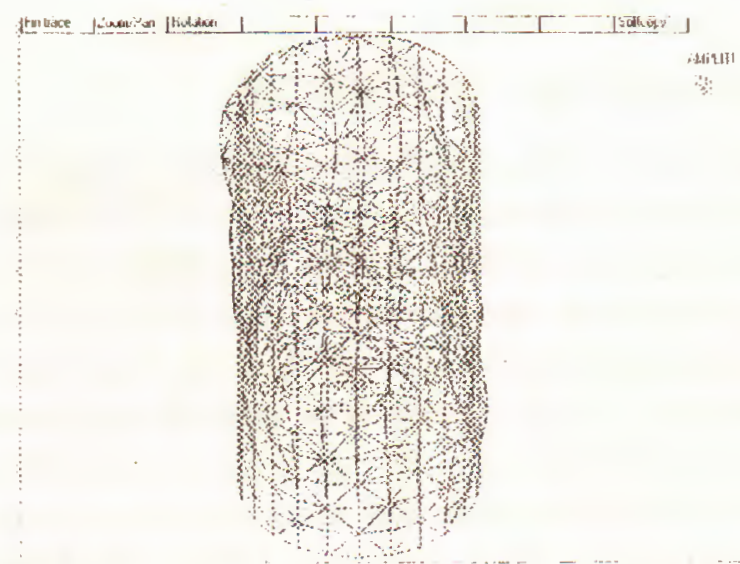

Fig. 8. The unstable forms in the longitudinal direction when $\alpha=60^{\circ}$

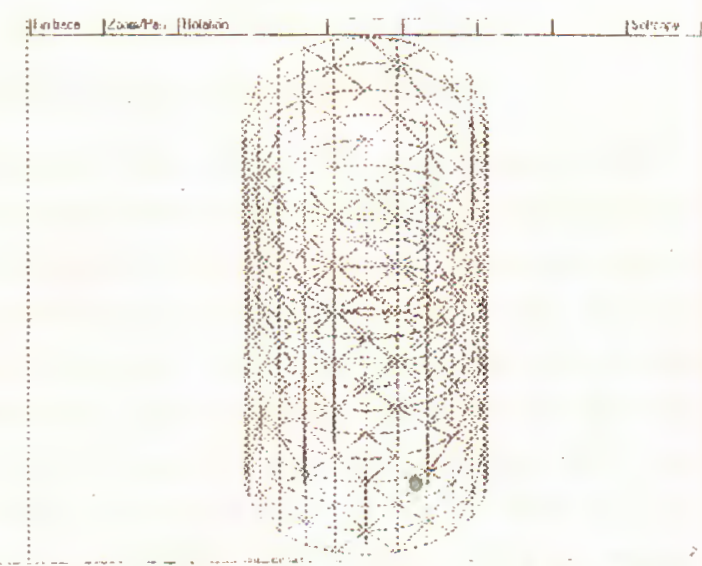

Fig. 9. The unstable forms in the longitudinal direction when $\alpha=45^{\circ}$

\section{Conclusions}

This investigation shows that generally the calculated results via software Castem 2000 for stability problems with different loads have a good agreement with analytical classical results. The long cylinder give better agreement than the short in the case when cylinder is subjected to pressure. The influence of the radius and length of isotropic cylinders on unstable forms and values of critical stress are investigated. The influence of angles of fibers on unstable behaviour of laminate composite shell is considered. The given results and corresponding programs are useful to estimate capacities when applying Castem 2000 in solving more complex stability problems for arbitrary shell.

This publication is completed with financial support from the National Basis Research Program in Natural Sciences.

\section{REFERENCES}

1. Volmir A. C. Stability of deformed systems. Moscow 1967 (in Russian)

2. Tran Ich Thinh. Composite material. Mechanics and structural calculation. Education Publishing house, 1994 (in Vietnamese).

3. Zienkiewicz O. C., Cheung Y. K. The Finite Element Method in structural and continuum Mechanics. 1967 McGraw-Hill Publishing Company Limited.

4. Ngo Huong Nhu. Stability behaviour of laminated composite plates subjected to complex loading. Proceeding- Acter of International colloquium in mechanics of solids, fluids, structures and interactions. Nha Trang August 2000. p 645- 655.

5. C.E.A/D.M.T/L.A.M.S. Castem 2000 Recueil D'exemples commentes. 1992 (in French)

Received April 18, 2001 